\title{
A satellite-based analysis of the Val d'Agri Oil Center (southern Italy) gas flaring emissions
}

\author{
M. Faruolo ${ }^{1}$, I. Coviello ${ }^{1}$, C. Filizzola ${ }^{1}$, T. Lacava ${ }^{1}$, N. Pergola ${ }^{1}$, and V. Tramutoli ${ }^{2,1}$ \\ ${ }^{1}$ Institute of Methodologies for Environmental Analysis, National Research Council, Tito Scalo, Italy \\ ${ }^{2}$ School of Engineering, University of Basilicata, Potenza, Italy \\ Correspondence to: M. Faruolo (mariapia.faruolo@imaa.cnr.it)
}

Received: 28 February 2014 - Published in Nat. Hazards Earth Syst. Sci. Discuss.: 6 June 2014

Revised: 9 September 2014 - Accepted: 10 September 2014 - Published: 17 October 2014

\begin{abstract}
In this paper, the robust satellite techniques (RST), a multi-temporal scheme of satellite data analysis, was implemented to analyze the flaring activity of the Val d'Agri Oil Center (COVA), the largest Italian gas and oil pre-treatment plant, owned by Ente Nazionale Idrocarburi (ENI). For this site, located in an anthropized area characterized by a large environmental complexity, flaring emissions are mainly related to emergency conditions (i.e., waste flaring), as industrial processes are regulated by strict regional laws. While regarding the peculiar characteristics of COVA flaring, the main aim of this work was to assess the performances of RST in terms of sensitivity and reliability in providing independent estimations of gas flaring volumes in such conditions. In detail, RST was implemented for 13 years of Moderate Resolution Imaging Spectroradiometer (MODIS) medium and thermal infrared data in order to identify the highly radiant records associated with the COVA flare emergency discharges. Then, using data provided by ENI about gas flaring volumes in the period 2003-2009, a MODIS-based regression model was developed and tested. The results achieved indicate that the such a model is able to estimate, with a good level of accuracy $\left(R^{2}\right.$ of 0.83$)$, emitted gas flaring volumes at COVA.
\end{abstract}

\section{Introduction}

Gas flaring is a high-temperature oxidation process used to burn combustible components, mostly hydrocarbons, of waste gases deriving from oil and gas production operations (EPA, 2012). In all industrial plants, the primary purpose of a flare is to act as a safety device to protect vessels or pipes from over-pressuring due to unplanned upsets, particularly at gas processing plants. In an emergency situation where equipment becomes over-pressured, special safety systems automatically release gas to flare stacks, to avoid fires and explosions of the plant (Ohio Epa, 2012).

Gas flaring is recognized as a waste of a valuable nonrenewable source of clean energy and an added load of carbon emissions to the atmosphere (Elvidge et al., 2007; Ismail and Umukoro, 2012), contributing to global warming, causing climate change and affecting the environmental quality and human health in the areas close to the flares. This happens especially in countries lacking pipelines and other gas transportation infrastructure as well as processing plants to handle natural gas and where no efficient and effective regulations on flaring are applied (Cholakov, 2009; Ohio Epa, 2012; Ismail and Umukoro, 2012). The World Bank has estimated that 150 billion cubic meters of natural gas are being flared annually, equivalent to $30 \%$ of the European Union's gas consumption. Through gas flaring, about 400 million tons of $\mathrm{CO}_{2}$ (representing about $1.2 \%$ of global $\mathrm{CO}_{2}$ emissions) are added annually into the atmosphere (World Bank, 2012).

Considering the environmental impact of gas flaring both at the global and local scale, a global effort to track progress on flaring monitoring, also using independent tools able to provide continuous and systematic information on this phenomenon (Ismail and Umukoro, 2012), is required.

Recently, satellite observations have been widely employed to investigate this phenomenon, demonstrating the potential of providing independent estimates of gas flaring volumes injected into the atmosphere. Pioneering works on this topic date back to the 1970s (Croft, 1978, Muirhead and Cracknell, 1984). They were focused on nighttime gas flare 
detection and demonstrated the capability of satellite sensors to derive useful information on human activities at a global scale (Welch, 1980; Muirhead and Cracknell, 1984). More recently, it has been demonstrated that multiyear data sets of satellite data can be used for the systematic observation of flares and estimation of flared gas emission volumes globally (Elvidge et al., 2012). To this aim, given the wide spatial distribution and possible gas flaring fluctuation over time, particular attention has to be given to sensors able to collect data globally, on a frequent basis and having the spectral capability for detecting gas flaring and/or related phenomena. Moreover, long-term data archives, together with the potential for long-term homogeneous observations in the future, are preferable for selecting the proper satellite technology to be employed for this purpose.

Although none of the currently available Earth observation satellite sensors have been primarily designed for gas flaring observation, several systems have a capability to indirectly detect gas flares, based on the radiative emissions of sources (Elvidge et al., 2007). Gas flares are point sources of persistent fire activity, occurring frequently and with lower average fire radiative power (FRP) $\mathrm{km}^{-2}$ values than other fire types (Elvidge et al., 2011). As objects with high temperatures $(>800 \mathrm{~K})$, they radiate all wavelengths of the electromagnetic spectrum. In particular, as shown in Fig. 1, the higher the temperature of the body, the higher total amount of the emitted radiation, according to the Plank's law (area under the different curves in Fig. 1), while the wavelength relative to the peak of the maximum emission decreases inversely with temperature, according to Wien's displacement law.

The first satellite gas flaring survey, at global level, was assessed by the National Oceanic and Atmospheric Administration (NOAA), with the aim of improving the reliability and consistency of gas flaring data, as part of the GGFR (Global Gas Flaring Reduction) partnership funded by the World Bank in 2002. First, the DMSP (Defense Meteorological Satellite Program) OLS (Operational Linescan System) data, acquired during nighttime in its very sensitive visible band ( 0.5 to $0.9 \mu \mathrm{m}$, at $2.7 \mathrm{~km}$ spatial resolution), were collected and analyzed to derive the magnitude of gas flaring on the basis of its light (Elvidge et al., 1997, 2001). Calibration models were then developed to estimate gas flaring volumes for individual countries. Since 2005, NOAA and GGFR have been continuing to use such data to produce annual estimates of gas flaring volumes at both the national (about 60 countries worldwide, not including Italy) and global scales (Elvidge et al., 2009).

To overcome some shortcomings of such data (e.g., coarse spatial resolution, limited dynamic range and lack of in-flight calibration, more details in Elvidge et al., 2009), MODIS (Moderate Resolution Imaging Spectroradiometer) records, acquired at medium (MIR) and thermal infrared (TIR) channels (at $1 \mathrm{~km}$ spatial resolution), have been used. In particular, a combination between such bands was used. The MIR

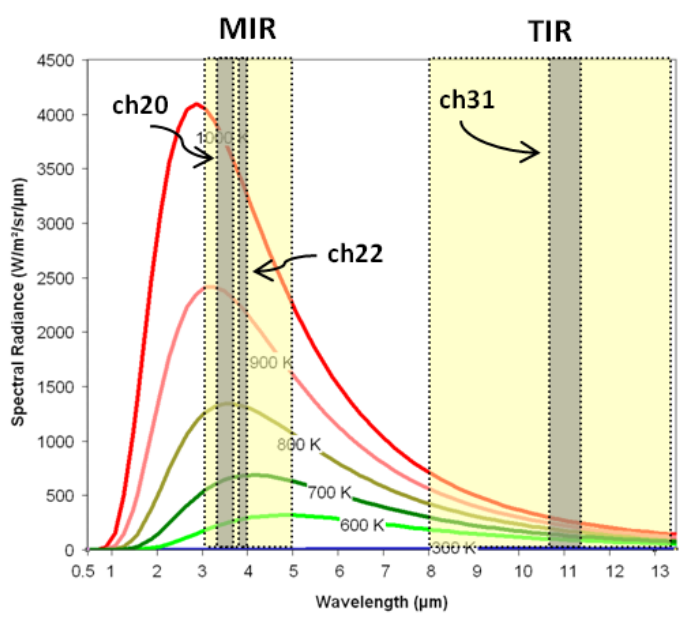

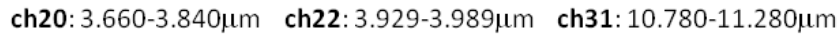

Figure 1. Variation in the quantity of radiation emitted in the visible-thermal infrared region by an object at different temperatures. Yellow boxes identify the medium and thermal infrared regions of the electromagnetic spectrum used in the remote sensing for hot spot detection, located in atmospheric windows, whereas gray bars show the spectral range covered by MODIS (Moderate Resolution Imaging Spectroradiometer) bands (i.e., ch20, ch22 and ch31) used in these analyses.

channels at 3-4 $4 \mathrm{~m}$ (i.e., bands 20 or 22 ) are more sensitive to the presence of high temperature sources (hot spots, fires or flares) than the thermal infrared bands (at 11-12 $\mu \mathrm{m}$, i.e., channel 31) (Fig. 1). This is why the difference between brightness temperatures (BT) in the MODIS MIR and TIR bands is generally suitable and widely used to identify possible hot sources (Flasse and Ceccato, 1996; Dehn et al., 2000; Wright et al., 2002; Giglio et al., 2003; Kervyn et al., 2006; Baldassarre et al., 2009; Van Manen and Dehn, 2009; Elvidge et al., 2011, Marchese et al., 2011, 2012; Steffke and Harris, 2011). In recent years, the NGDC (National Geophysical Data Center) suggested a pure MIR-based MODIS algorithm for flare detection at night (using band 20 minus band 22) and characterization (Elvidge et al., 2011, 2012).

Since 2011, the NGDC staff has been working on Visible Infrared Imaging Radiometer Suite (VIIRS) data, which offer a substantial number of improvements over its predecessors in terms of spatial resolution $(375-750 \mathrm{~m})$, dynamic range, quantization, calibrations and the availability of spectral bands suitable for discrimination of thermal sources. Based on these data, NGDC has developed a system called "Nightfire", which detects and characterizes sub-pixel combustion sources worldwide using VIIRS nighttime multispectral data. The spectral bands utilized span the visible, nearinfrared, shortwave infrared (SWIR) and MIR wavelengths (Elvidge et al., 2013; NOAA-NGDC, 2013).

Recently, Casadio et al. (2012a, b) demonstrated that the combined use of SWIR nighttime radiances acquired by 
the Along Track Scanning Radiometer (ATSR) and the Advanced Synthetic Aperture Radar (ASAR, on the Envisat satellite) sensors can be used for the detection, characterization and monitoring of offshore oil/gas extraction platforms.

These studies and pioneering works are generally developed to investigate gas flares at a global or country scale, analyzing multi-source data sets jointly and looking for major, very intense sources, characterized by large flare emissions (from a few to hundreds of BCM, billion cubic meters per year) in countries where gas re-injection or monetization is not available. To our knowledge, up to now no studies have proposed to investigate, by satellite observations, a single gas flare source characterized by low/moderate emission rates (less than 1 million cubic meters per year), which try to provide a comprehensive analysis of the source from its thermal characterization to the estimation of flared gas volumes. This work moves in this direction because, for the first time, a satellite-based analysis of waste flaring activity from a single onshore gas and oil pre-treatment plant (i.e., the Ente Nazionale Idrocarburi - ENI - Val d'Agri Oil Center - COVA) located in the Basilicata region (southern Italy) with moderate emission rates (i.e., with flaring emission volumes of hundreds of thousands of cubic meters per year) was performed. Obviously, results achieved in this work could be used to initialize and assess an atmospheric dispersion model which could help in the comprehensive analysis of the effect produced by COVA at the regional scale.

In detail, 13 years of nighttime Aqua and Terra MODIS thermal data were analyzed, implementing the robust satellite techniques (RST) approach (Tramutoli, 2005, 2007), with the aim of identifying highly radiant records associated with the main blowdown events (i.e., waste flaring) occurring at the COVA during emergency discharges. Using the data provided by ENI about flare emission volumes between 2003 and 2009, a MODIS-based regression model, able to give reliable and independent information on COVA flaring emission volumes, was finally developed and tested.

\section{Case study: the Val d'Agri Oil Center (COVA)}

ENI, the largest Italian oil- and gas-producing company, is the operator of the Val d'Agri concession in the Basilicata region. The COVA plant is its oil/gas gathering and treating center in that region (Fig. 2). It is located in the industrial area of Viggiano (PZ), a small village in southern Italy, and covers an area of $171700 \mathrm{~m}^{2}$.

It is worth noting that the COVA is not only the largest gas and oil pre-treatment plant in Italy but also the largest onshore European reservoir, the only located in an anthropized area characterized by a large environmental complexity where nature coexists with anthropogenic activities, the latter having potentially high environmental impact. Additionally, the considerable biodiversity which characterizes the Val d'Agri is partly included in the protected area of the Appennino Lucano Val d'Agri Lagonegrese National Park.

COVA began operation in 1996 with the name Monte Alpi; in the following years (from 2001 to 2006), with the increase of production lines (from one to five), it became the Val d'Agri Oil Center (i.e., COVA). Such a plant is aimed at the separation and the further processing of the three phases present in the extracted fluid (crude oil, gas and water). In 2009, COVA infrastructure was modified to treat a higher gas amount, also with higher values of acidity and a higher GOR (gas / oil ratio) (Rapporto Istruttorio, Regione Basilicata, 2011), as well as to optimize combustion processes. These recent upgrades modified the emissions framework of the plant compared to its original configuration (Local Report ENI, 2012). Crude oil is extracted from 26 wells, currently in production in the area and transported to the COVA through about $100 \mathrm{~km}$ of pipeline. The nominal capacity of treatment authorized for the entire plant is equal to $16500 \mathrm{~m}^{3} \mathrm{day}^{-1}$ of oil (corresponding to about 104000 barrels day $^{-1}$ ) and 3.1 million $\mathrm{Sm}^{3} \mathrm{day}^{-1}$ of associated gas (to crude oil). Oil produced is carried to ENI's refinery in Taranto via a $136 \mathrm{~km}$ pipeline, while gas produced is treated at the COVA and then delivered to the SNAM (Società Nazionale Metanodotti) national grid system. To better understand the COVA entity at national scale, in Fig. 3, the 2012 COVA oil and gas production are shown: the COVA oil production represents about the $82 \%$ of the Italian amount (Fig. 3a) while such a plant produces the $50 \%$ of Italian natural gas (Fig. 3b).

\section{Data}

In this section, all the data used in this work, both the satellite records and the validation data provided by ENI, are described.

It should be stressed that for the aims of this work, both satellite and in situ data, available at different temporal scales, were aggregated on an annual basis, according to all literature studies devoted to gas flaring volumes estimation by satellite (Elvidge et al., 2009, 2011). Such works are focused on annual estimates of gas flared in order to monitor this trend over the years, with the aim both of filling the gap about such data produced only by governments and petroleum companies and of better assessing the efficacy of efforts made to reduce gas flaring. This temporal aggregation, although possibly affecting the accuracy of the regression model, allows us to reduce the observational issues (e.g., cloud cover, high satellite zenith angles) of the satellite system used.

\subsection{MODIS data}

In this study, images acquired during nighttime by MODIS sensors, aboard EOS (Earth observing system) Terra and Aqua satellites, passing over the area of interest between 


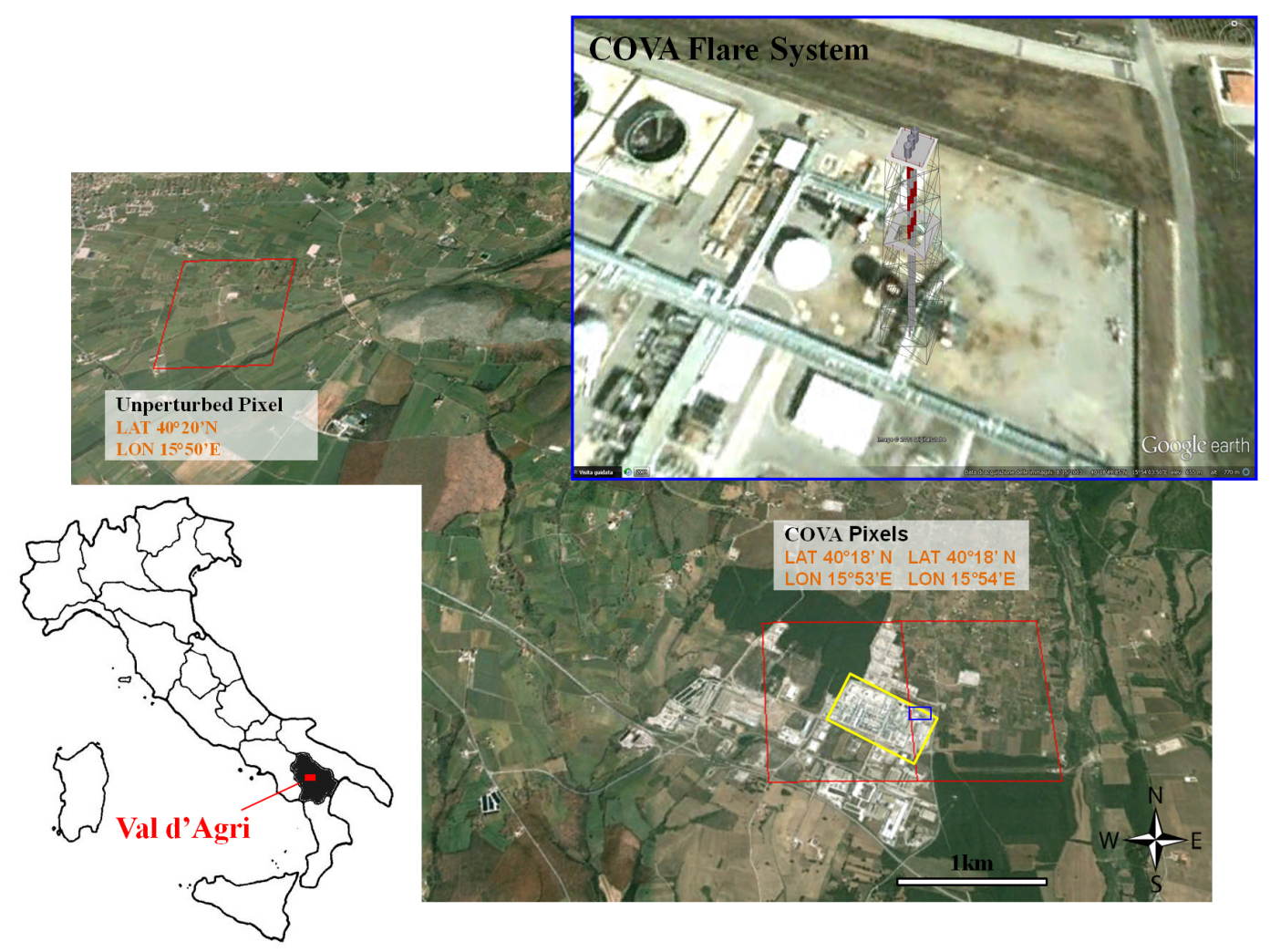

Figure 2. Map of the COVA site, highlighted by the yellow box (adapted from Google Earth ${ }^{\circledR}$ ); the red boxes represent the MODIS pixels position on the re-projected grid covering the COVA and the unperturbed area used in the analyses (see text); in the top right corner, the COVA flare system is detailed (blue box).

20:00 GMT and 01:30 GMT, were collected and processed. Specifically, the MODIS data multiyear archive, available at the Institute of Methodologies for Environmental Analysis (IMAA) of the National Research Council (CNR), Tito Scalo (Italy), was used. The brightness temperature (BT) measured in the MODIS MIR and TIR bands, i.e., channels 20 (3660$3840 \mu \mathrm{m}), 22(3929-3989 \mu \mathrm{m})$ and $31(10780-11280 \mu \mathrm{m})$ (see Fig. 1), at $1 \mathrm{~km}$ of spatial resolution, were analyzed to identify major thermal emissions as well as to quantify the radiant energy emitted by the investigated pixels. In detail, multiyear data sets of MIR and TIR BTs measured from 2000 to 2012 (about 10000 data points) were created for three pixels: two covering the COVA site and one representing an unperturbed area nearby (Fig. 2). By re-projecting, resampling and colocating procedures, in fact, the COVA area falls within two MODIS pixels (Fig. 2); therefore, the contribution of both these two pixels was taken into account in the study. Additionally, the response of an unperturbed area, i.e., not impacted by the presence of industrial facilities (Fig. 2), was investigated to better assess the accuracy and reliability of the proposed methodology in characterizing the thermal activity at COVA site. The unperturbed pixel is located slightly to the NW, about $6 \mathrm{~km}$ from the COVA, and in a predominantly vegetated area, which ensures that no adverse impact to the environment due to anthropogenic activities can modify its spectral response. To better assess the effectiveness of such a choice, the range correlation analysis suggested by Noguchi et al. (2011) was computed. The results achieved show that, for all of the 13 investigated years, $\rho$ is lower than 0.95 , confirming the effectiveness of this selection. For each year and each day of the year, the BT values in MIR and TIR channels for the three investigated pixels were extracted; data were analyzed on an annual basis, considering only data acquired at a zenith angle lower than $40^{\circ}$ (to reduce the impact of the resampling and path radiance effects) and not contaminated by clouds presence, which could mask the signal coming from the COVA. Cloudy pixels, identified by applying the standard cloud detection scheme described in Cuomo et al. (2004), represent almost the $50 \%$ of full analyzed data set. After the application of the cloud and the zenith angle filters, 7200 values (as the sum of those acquired in bands 20, 22 and 31) were finally analyzed for each pixel.

\subsection{ENI data}

To support this research activity, ENI provided data about (i) gas (Standard cubic meter, $\mathrm{Sm}^{3}$, daily values) and (ii) oil $\left(\mathrm{m}^{3}\right.$ and barrel, daily values) production from 2000 to 2012 and 

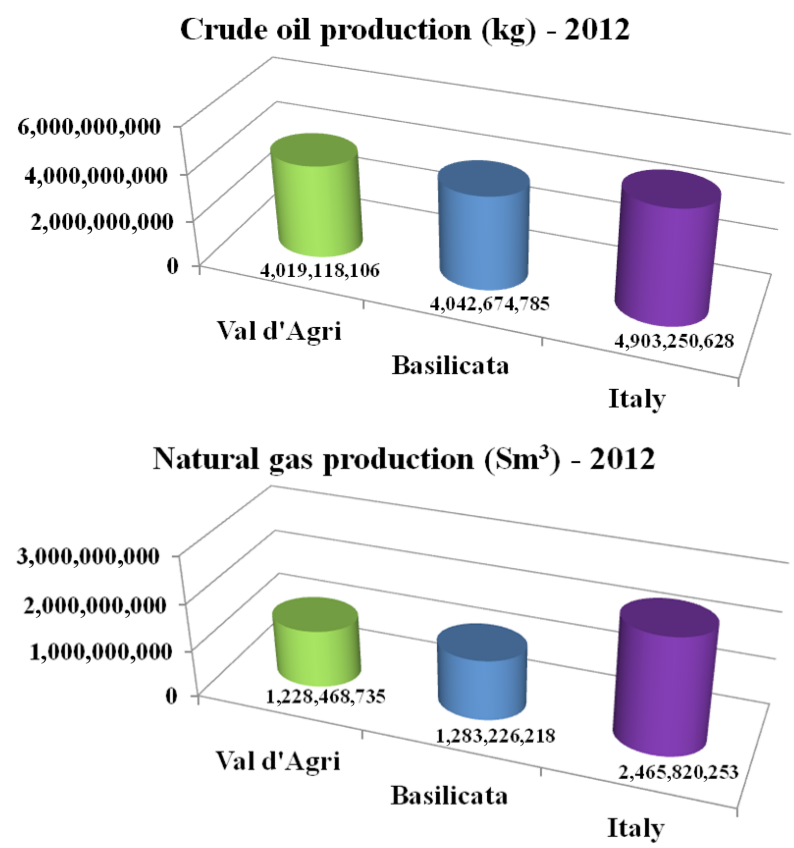

a)

Figure 3. Oil and gas production for Italy, Basilicata region and COVA (Data processed by http://unmig.sviluppoeconomico.gov.it/ unmig/produzione/produzione.asp).

(iii) gas flaring emissions from 2003 to 2009 (monthly values in $\mathrm{Sm}^{3}$ ).

In detail, regarding gas flaring volumes, the flare system at COVA (consisting of three elevated flares and one on the ground, see Fig. 2) is used for emergency discharges to burn the excess gas sent to the flares as well as during normal operations for ensuring the safety of the plant (Local Report ENI, 2012). Note that the volumes of gas flared provided by ENI are regarding the main blowdown events (i.e., waste flaring) occurring in the investigated time period. The peculiarity of such s plant is that $60-80 \%$ of gas is flared during emergency depressurization operations.

\section{The methodology}

Studies on gas flaring with MODIS data have suggested using the BT difference between channel 22 (more recently channel 20, Elvidge et al., 2012) and channel 31 (e.g., Elvidge et al., 2009, 2011) (gray bars in Fig. 1 enhance their spectral location) to detect flares presence and quantify their radiant energy. In particular, Elvidge et al. (2012) proposed the use of MODIS channel 20 rather than channel 22 for improving the discrimination between different types of hot sources as it is more sensitive to the presence of emitting bodies at very high temperatures. Values of the MIR-TIR BT difference greater than $5 \mathrm{~K}$ have been arbitrarily defined as thermal anomalies of the investigated signal and used in studies to determine the presence of hot sources at night (Flasse and
Ceccato, 1996; Dehn et al., 2000; Kervyn et al., 2006; Wright et al., 2002; Giglio et al., 2003; Van Manen and Dehn, 2009; Elvidge et al., 2011; Steffke and Harris, 2011).

In contrast to such fixed threshold methods, in this paper an automatic change-detection scheme (named RST, i.e., robust satellite techniques, Tramutoli, 2005, 2007), based on the analysis of multiyear series of satellite data, colocated in the spatiotemporal domain, is used. The RST methodology may assure, in fact, the automatic and reliable identification of highly radiant values associated with the flaring of gas. In detail, the methodology implemented to define a satellitebased regression model for estimating gas flaring volumes emitted by the COVA in emergency conditions (i.e., waste flaring) was based on the following steps:

1. pre-processing (e.g., calibration, geolocation) and analysis (e.g., cloud detection, zenith angle filtering) of MIR (channels 20 and 22) and TIR (channel 31) MODIS radiances between 2000 and 2012;

2. implementation of the RST approach to select the highly radiant records associated with gas flaring activities; according to its definition, as explained in the following section, RST should be able to pick up only the most "anomalous" thermal emissions in the time series, i.e., the emissions which are likely to be associated with the main flaring events;

3. computation of the FRP for the anomalous records previously identified by RST;

4. FRP correlation with the actual gas flaring volumes (provided by ENI) to define a MODIS-based regression model for an indirect estimation of COVA gas flaring emission volumes.

Figure 4 shows a flowchart of the methodology developed.

\subsection{The RST approach}

The robust satellite techniques approach is a changedetection scheme, based on the analysis of multiyear series of satellite data acquired in homogeneous spatiotemporal conditions (i.e., same geographic area, same month and hour of acquisitions) for a previous characterization of the signal investigated $V(x, y, t)$ in terms of expected value and natural variability (i.e., the "reference fields") for those specific conditions. Such reference fields are usually expressed by the monthly temporal mean $\mu_{V(x, y)}$ and the standard deviation $\sigma_{V(x, y)}$ of the signal $V$ and are computed for each pixel of the scene, processing all cloud-free records and removing, by an automatic and iterative procedure, outliers from the series (Tramutoli, 2005).

Signal anomalies are automatically identified in the spatiotemporal domain by ALICE (Absolutely Local Index of 


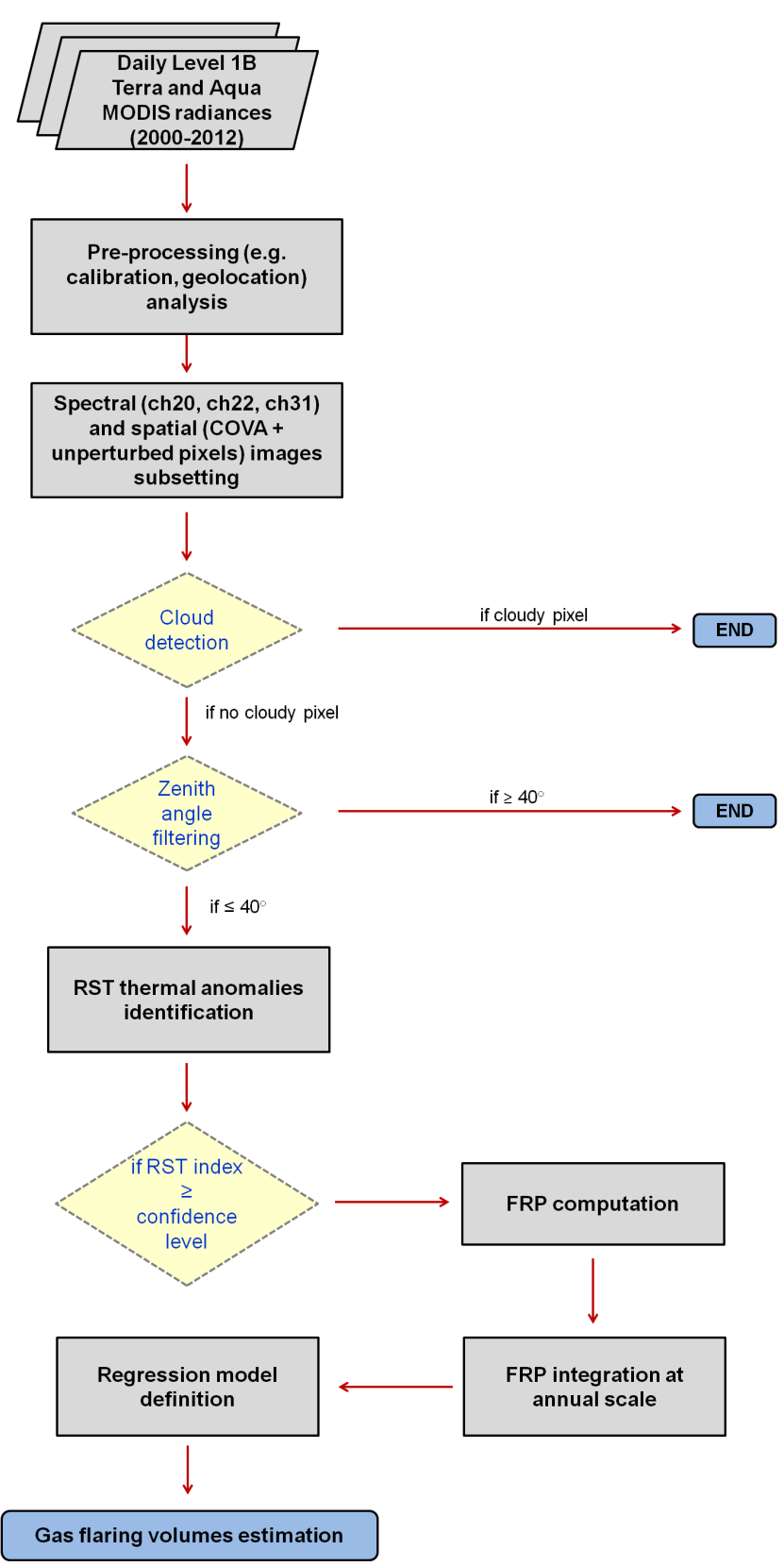

Figure 4. Flowchart of the developed methodology for gas flaring volume estimation.

Change of the Environment), defined as follows:

$\otimes_{V}(x, y, t) \equiv \frac{V(x, y, t)-\mu_{V}(x, y)}{\sigma_{V}(x, y)}$,

which provides, at pixel level, a measure of the deviation of the recorded signal $V(x, y, t)$ from its expected (in unperturbed or normal conditions) value $\left(\mu_{V}\right)$ and automatically compares this deviation with its normal variability $\left(\sigma_{V}\right)$, which includes all the possible noise sources not related to the event monitored. The signal $V(x, y, t)$ to be analyzed is chosen according to the phenomenon to be studied and may correspond with the measurement made in a single spectral band or can derive from a proper combination of several channels (Tramutoli, 1998).

Regarding its construction, ALICE is a standardized variable characterized by a Gaussian behavior (i.e., with mean equal to zero and standard deviation equal to 1 ). This means that the probability of occurrence of values higher than \pm 2 standard deviations is less than $2.28 \%$ and it becomes lower than $0.13 \%$ for values higher than 3 .

The RST approach has been widely used in the past to study several environmental phenomena and, in particular, to investigate sources at high temperature, characterized by a 1-D time-dependent distribution (e.g., volcanoes) and a 2-D dependence, in the spatiotemporal domain (e.g., fires) (Baldassarre et al., 2009; Filizzola et al., 2010; Marchese et al., 2011, 2012).

For studying the gas flaring phenomenon, following the indications of Elvidge et al. (2009, 2011, 2012), the signals to investigate are the combinations $\mathrm{MIR}_{22}-\mathrm{TIR}_{31}$ and $\mathrm{MIR}_{20} \mathrm{TIR}_{31}$, so two ALICE indices were defined and analyzed:

$\otimes_{20-31}(x, y, t)=\frac{B T_{20-31}(x, y, t)-\mu_{20-31}(x, y)}{\sigma_{20-31}(x, y)}$,

$\otimes_{22-31}(x, y, t)=\frac{B T_{22-31}(x, y, t)-\mu_{22-31}(x, y)}{\sigma_{22-31}(x, y)}$.

Generally, for both indices, high values are expected to be detected in the presence of significantly (on a statistic basis) anomalous hot spots. Considering that the COVA is a stable source, persistent in space and time, ALICE indices are not expected to reach very high levels in case of normal operation of the flare system. On the other hand, the highest ALICE index values should be related to the most highly radiant records associable to the major fluctuations in the COVA combustion operations and/or to gas flaring in emergency conditions (extremely high and intense burst of flames are generally associated with these anomalous situations). Therefore, from this point of view, the COVA represents a significantly different hot source compared to previous RST applications. Thus, in order to study ALICE behaviors for such a source and to investigate the reliability of this approach to describe the flaring phenomenon, eight values of both the ALICE indices, from 1.0 up to 4.5 (with an increase of 0.5), were analyzed.

As a first step, the two investigated signals (Eqs. 2 and 3) were analyzed both for the COVA and the unperturbed pixel in order to verify their capability of detecting and characterizing the investigated phenomenon. In detail, the behavior of the two signals for the unperturbed pixel was analyzed to define the residual error (i.e., false positives) for each index. It means that the same analysis carried out for the COVA site was carried out also for the unperturbed one, for which, obviously, no (or residual) anthropogenic thermal anomalies are 
expected. Possible errors committed during the identification of thermal anomalies at COVA (false identifications, i.e., local warming effects not related to industrial processes) were then computed as the percentage of thermal anomalies identified over the unperturbed pixel at a specific confidence level (c) of the investigated index. Also, the residual uncertainty due to the geolocation errors in MODIS data is included into the once previously defined.

Figure 5 describes the occurrence (in percentage, relative to the total number of analyzed images) of thermal anomalies detected over both the COVA and the unperturbed pixels. Results achieved by using the two ALICE indices, at all the different selected confidence levels, are reported.

Looking at Fig. 5, some observations can be made:

- regarding the COVA pixel, as expected, a higher number of thermal anomalies is detected compared to the unperturbed pixel, regardless of the ALICE index and the confidence level used;

- over COVA, the two ALICE indices behave in a very similar way, with a slightly better sensitivity of the $\mathrm{ALICE}_{20-31}$ than $\mathrm{ALICE}_{22-31}$ for $c \geq=1.5$;

- concerning the unperturbed pixel, a more distinctive behavior of the two indices is instead observed, with a more reliable $\mathrm{ALICE}_{20-31}$ which, already at $c=1.5$ and different than $\mathrm{ALICE}_{22-31}$, shows very low rates of false positives. However, it should be stressed that the absolute maximum percentage of false identifications is $8.4 \%$ (observed for $\mathrm{MIR}_{22}$ - $\mathrm{TIR}_{31}$ at the lowest confidence level, confirming the high reliability of the RST approach);

- in general, a clear distinction between the two sources can be observed at the lowest confidence levels of both the ALICE indices (i.e., between 1.0 and 2.0) as, for ALICE $\geq 2.5$, the number of thermal anomalies detected for both the pixels is very low. This circumstance, while obvious for the unperturbed pixel, is likely to be ascribed to the stability of the thermal source for COVA.

In conclusion, this analysis reveals

- in terms of ALICE indices: the most suitable index for studying the COVA flaring is the $\mathrm{ALICE}_{20-31}$ (Eq. 2) because the rate of possible false positives is very low (i.e., less than $2.7 \%$ ), regardless of $c \geq 1.0$ (high reliability). Moreover, such an index shows a better sensitivity than the other one in identifying instances at very high temperatures (high sensitivity);

- in terms of confidence levels: the best confidence level range is between 1.5 and 2.0, where the best tradeoff between statistical population and reliability seems to be assured.

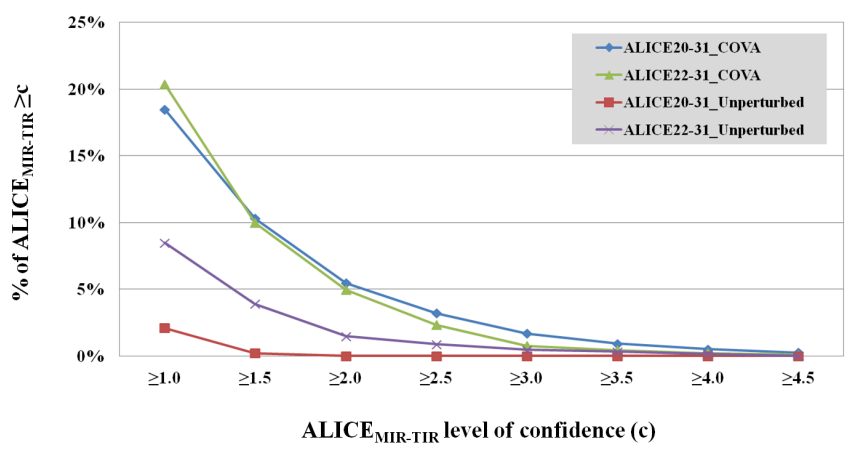

Figure 5. Percentage of anomalous value occurrence (i.e., ALICE $_{\text {MIR-TIR }} \geq c$ ) compared to the total number of analyzed images (in the 2000-2012 time period) over the COVA and the unperturbed pixel for the two investigated signals (i.e., $\mathrm{MIR}_{20}-\mathrm{TIR}_{31}$ and $\mathrm{MIR}_{22}-\mathrm{TIR}_{31}$ ).

Concerning the sources of thermal anomalies identified over the unperturbed pixel, apart from local warming effects, they could be related to (i) clouds edges not correctly identified by the cloud masking procedure; (ii) low quality data; (iii) fires possibly occurred in the area. Although fires can be considered "actual" thermal anomalies, not having any independent and reliable information about their possible occurrence regarding detections, we preferred to consider all of them as false positives, providing a more conservative analysis. Therefore, the analysis seems to suggest that with the chosen ALICE index and confidence levels, a maximum residual error of about $3 \%$ in hot spot detection should be accounted for.

To better assess the nature of the detected hot spots and to verify their possible relationship with COVA plant operations and combustion processes for the identified "hot" pixels (i.e., the ones having values of $\mathrm{ALICE}_{20-31} \geq 1.5 / 2.0$ ), the excess of radiance (defined as the numerator in Eq. (2), i.e., the difference between the measured $\mathrm{MIR}_{20}-\mathrm{TIR}_{31}$ and the mean value expected to be observed for such a band combination in normal conditions) was computed. In detail, as earlier explained (see Sect. 3.1), as the COVA plant is located inside two MODIS pixels (Fig. 2), for the computation of the excess of radiance the contributions of both pixels were summed only when both ALICE $20-31$ were over 1.5 (or 2.0) (in 3 and $1 \%$ of cases, respectively), otherwise only the one over the selected confidence level was considered.

Such excesses were then aggregated at annual basis, providing one value for each year from 2000 to 2012. Afterwards, a correlation analysis was carried out comparing satellite-based radiance values achieved with the data provided by ENI about gas and oil production.

In Fig. 6, the excess of radiance computed for the two levels of confidence of $\mathrm{ALICE}_{20-31}$ is reported, together with the COVA gas (in $\mathrm{Sm}^{3}$ ) and oil $\left(\mathrm{m}^{3}\right)$ production values between 2000 and 2012 (histogram bars). 
Table 1. Correlation coefficients $(R)$ between the excess of radiance measured by satellite and COVA gas and production in the period 2000-2012.

\begin{tabular}{lcc}
\hline$R$ & $\begin{array}{c}\text { Radiance excess } \\
\left(\mathrm{ALICE}_{20-31} \geq 2.0\right)\end{array}$ & $\begin{array}{c}\text { Radiance excess } \\
\left(\mathrm{ALICE}_{20-31} \geq 1.5\right)\end{array}$ \\
\hline Gas production & $84 \%$ & $84 \%$ \\
Oil production & $82 \%$ & $84 \%$ \\
\hline
\end{tabular}

First, observing temporal trends shown in Fig. 6, the good agreement it is evident between production and satellite data as well as a lower radiant power for COVA estimated for the year 2012 by satellite analyses, despite gas and oil production higher than in previous years. This aspect can be explained by considering the history of the COVA production. Regarding gas (Fig. 6a), an increasing production is observed from 2000 until 2007, with a sharp decline in 2008, the year after which the production again increased. For oil (Fig. 6b), however, there was a quite constant increase in the production until 2006. Later, lower quantities of oil were produced, with the lowest production in 2009. Then, in the following years the production starts to increase. In 2010 and 2011, the production of oil and gas seemed to flatten out (both growing with the same relative increase). However, in 2012, compared with prior years, gas production increased with a rate higher than the one observed for oil, because of the higher GOR of the produced hydrocarbons. Since 2011, the facilities of COVA have undergone a series of adaptation and modernization activities (Rapporto Istruttorio, Regione Basilicata, 2011), still in progress, aimed at treating the crude oil extracted which has different chemical and physical properties (higher acid content and GOR). Such operations, obviously, have modified the emissions framework of the plant compared to its original configuration, resulting in lower emissions of some pollutants like $\mathrm{CO}_{2}$ and $\mathrm{NO}_{\mathrm{x}}$ and in better management of emergency operations (Local Report ENI, 2012).

Regarding the results referred to as the correlation analyses between the two data series, the computed correlation coefficients $(R)$ are reported in Table 1.

The $R$ values reported in Table 1 show that, for both the considered ALICE levels, the thermal radiative power of COVA, identified by RST and characterized in terms of the BT excess, is well correlated with the productivity of the plant (both in terms of oil and gas production). In particular, the records selected at ALICE $_{20-31} \geq 1.5$ show the highest correlation coefficients, with $R$ equal to 0.84 . Thus, the main conclusion of this analysis is that the RST approach, by using the $\mathrm{ALICE}_{20-31}$ index at values $\geq 1.5$, can determine thermal features that, with a high level of accuracy and reliability, are likely to be associated with the COVA productivity. Therefore, thermal emissions selected in this way using RST can be further used to better characterize the source in terms of gas emissions due to the flaring operations.

\subsection{The FRP computation}

To quantify the radiative energy emitted by the COVA during the flaring activity, the FRP was computed using the simplified formula proposed by Kaufman et al. (1998). The MODIS FRP retrieval is based on the relationship between the emitted fire energy and the middle infrared brightness temperature and is expressed as (Kaufman et al., 1998)

$\mathrm{FRP}=4.34 \times 10^{-19}\left(T_{4}^{8}-T_{4 \mathrm{~b}}^{8}\right)\left[\mathrm{W} \mathrm{m}^{-2}\right]$,

where $T_{4}$ and $T_{4 \mathrm{~b}}$ are the brightness temperatures (K) measured in the $4 \mu \mathrm{m}$ MIR region (i.e., band 22, although band 21 is used when band 22 saturates) for the target (i.e., the COVA, in this case) and the background pixels, respectively. The constant in Eq. (4) is derived empirically for the spectral interval of MODIS channels 21/22 (Kaufman et al., 1998). The empirical derivation of Eq. (4) is valid for FRP retrievals of hotspots with flaming temperatures ranging from 600 to $1500 \mathrm{~K}$ (Wooster et al., 2003).

In this paper, the FRP (Eq. 4) was computed for the thermal anomalies previously identified implementing ALICE $_{20-31} \geq 1.5$, in the period 2000-2012, again aggregating values annually. To define the mean radiance of the neighboring pixels, images having at least $50 \%$ clear pixels in the box surrounding COVA were taken into account.

The FRP temporal trend is reported in Fig. 7, where a clear increasing trend of FRP from 2000 to 2005 can be observed, with a maximum measured in 2005 ; in the following years, until 2012, FRP seems to be quite stable, with a mean value around $80 \mathrm{~W} \mathrm{~m}^{-2}$.

\subsection{The flaring regression model}

As previously explained (see Sect. 3.2), ENI provided data about the volumes of gas flared associated with the main blowdown events (i.e., waste flaring) occurring between 2003 and 2009. Satellite-based FRPs were then correlated with waste flaring volumes for the whole time period they were available. In Fig. 7, the temporal behavior of the two observables is shown. Looking at the figure, a pretty good correlation seems to appear and, in fact, a linear correlation coefficient equal to 0.97 was obtained.

On this basis, a MODIS-based linear regression model (with an imposed zero intercept, because an intercept different from zero means flaring emissions in the absence of production, and this has no a real physical meaning) was defined using the data between 2003-2008 as the ground truth to estimate the flaring emitted in 2009. The regression model (see Fig. 8) is

Gas Flared Volumes $\left(\mathrm{Sm}^{3}\right)=2442.7 \times \mathrm{FRP}(1.5)$, 

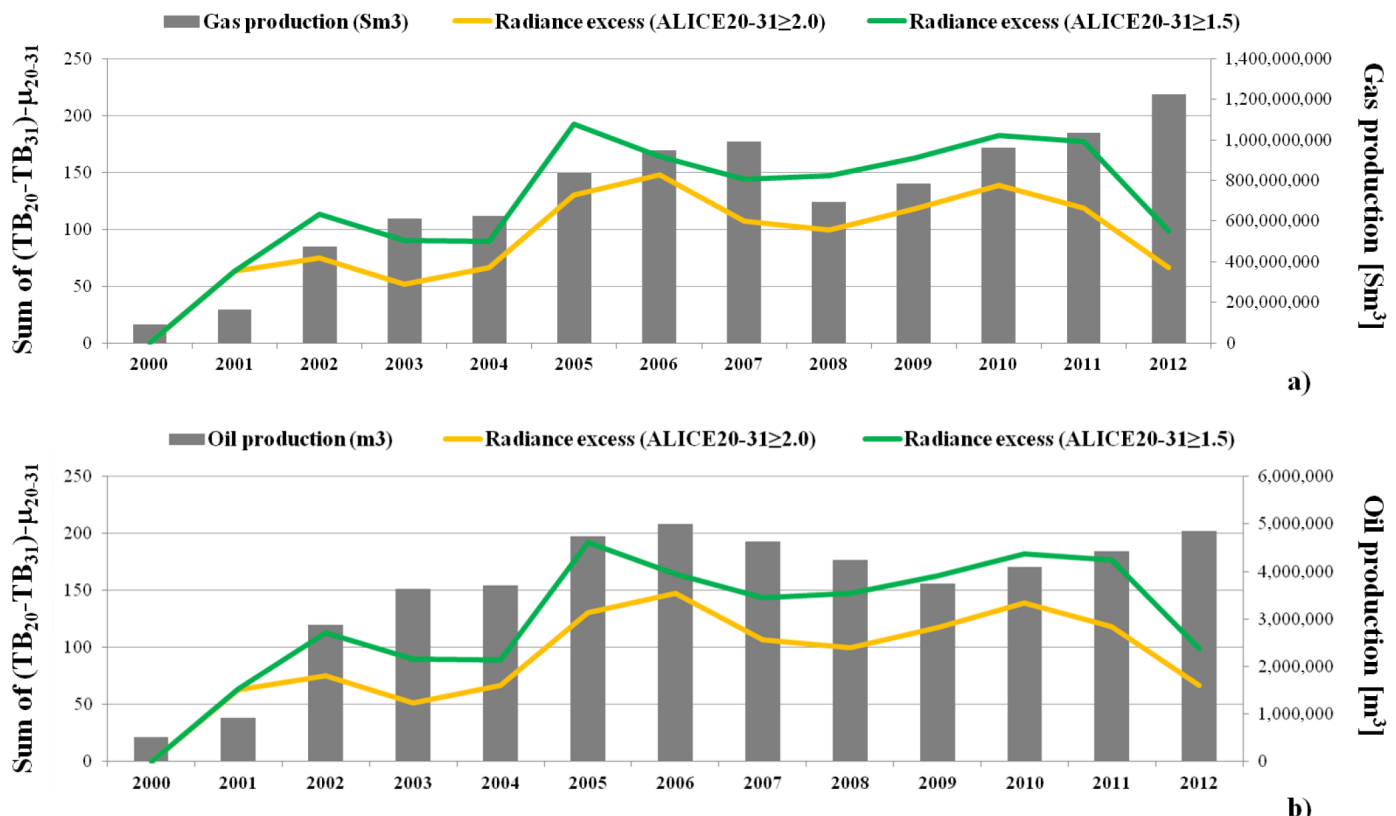

Figure 6. (a) Gas (in $\mathrm{Sm}^{3}$ ) and (b) oil (in $\mathrm{m}^{3}$ ) production in the period 2000-2012 and annual excess of radiance for COVA, computed in the same time period using the Eq. (2) at levels 1.5 (green line) and 2.0 (orange line).

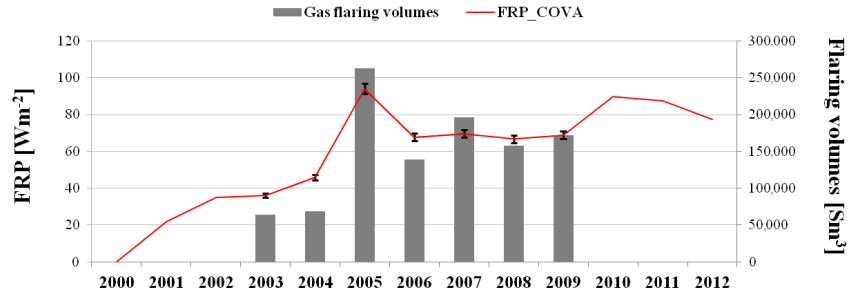

Figure 7. Annual FRP estimation for COVA in the period 20022012 (red line); temporal trend of gas flaring volumes (emitted during main emergency conditions) in the period 2003-2009 (histogram). For such a period the uncertainty of FRP (i.e., $3 \%$ ) is also reported.

where FRP(1.5) is the FRP computed over thermal anomalies identified for the COVA implementing ALICE $_{20-31} \geq 1.5$. The derived $R^{2}$ is 0.83 (Fig. 8).

By using the satellite-derived COVA FRP for 2009 $\left(69 \mathrm{~W} \mathrm{~m}^{-2}\right)$, the gas flaring volume emitted for the same year was estimated by applying the above-defined model and compared with the true value provided by ENI. Using the regression model, a volume of gas flared in 2009 was estimated equal to $167854 \mathrm{Sm}^{3}$. This should be compared to the actual value which, according to ENI measurements, is $171759 \mathrm{Sm}^{3}$. Therefore, the satellite-derived waste flaring is $2 \%$ underestimated compared to the real measurement.

These results are quite satisfactory considering the inherent limits of the proposed approach such as the temporal sampling (only nighttime data, annual aggregation) and the MODIS spatial resolution as well as other factors, like cloud

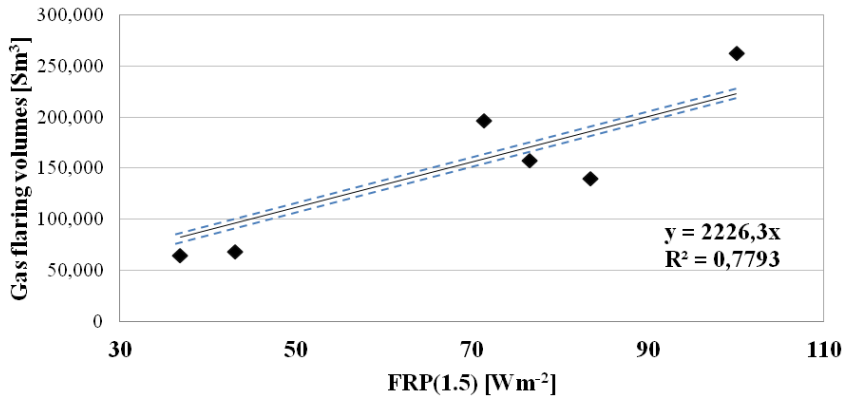

Figure 8. Linear regression model for gas flared volume estimation; the blue lines represent the uncertainty of the linear model (i.e., $2 \%$ ).

edges not well identified, residual false positives/negatives and missing data which may have affected the obtained achievements and which deserve future investigations.

\section{Conclusions}

Recently, satellite-based methodologies have been developed to detect and monitor the flares and the emitted gas volumes, at both a global and country scale, mainly focusing on sources characterized by relatively large flare emissions (from a few to hundreds of BCM).

In this paper, a satellite-based analysis of flaring activity of the onshore crude oil pre-treatment plant (i.e., the ENI Val d'Agri Oil Center, COVA) located in the Basilicata region (southern Italy), characterized by low/moderate 
emission rates (less than 1 million cubic meters), mainly due to emergency depressurization, was assessed. To this aim, 13 years of MODIS data acquired in its medium and thermal infrared bands were processed. For the first time, the RST approach was implemented to analyze such a phenomenon, allowing the examination of highly radiant records (compared to the normal behavior of the plant), which can be associated with the COVA flare emergency discharges. Once these anomalous values were identified, the emitted energy was estimated through the FRP to quantify the COVA radiant power during these emergency flaring activities. Using such a parameter and using the data provided by ENI about the volumes of gas flared in emergency conditions (i.e., waste flaring), occurring between 2003 and 2009, a MODIS-based regression model was defined for the COVA source and a very accurate estimation of gas flared in 2009 was obtained (error of about $2 \%$ ).

The results achieved are unique for the investigated area. They represent the first independent analysis of the area by using satellite data; in addition, they highlight the reliability of the proposed methodology for a thermal characterization of the site, with reference to the emergency flaring activity. Such outcomes are much more significant considering that the COVA, in contrast to most of similar industrial plants, is located inside a natural park in an area (i.e., the Val d'Agri) where the main activities are based on agriculture and farming.

With the very satisfactory results carried out by these preliminary analyses, further studies will be carried out in order to test the reliability and accuracy of the proposed methodology in estimating gas flared volumes of other oil plants worldwide, provided that in situ data (i.e., gas flaring volumes) are available. Additionally, thanks to the intrinsic exportability of the RST algorithm to different satellite systems and geographic areas, the performances of newgeneration satellite data (i.e., VIIRS) will also be investigated. Moreover, the capability of the proposed RST configuration to detect and characterize such combustion sources in daytime conditions will be also tested. In addition, the already-proposed RST configuration for hot spot detection (i.e., $\mathrm{RST}_{\text {VOLC }}$ ) will be tested and possibly adapted to this specific phenomenon.

Finally, the RST approach for hotspot detection may be applied to MSG-SEVIRI (Meteosat Second GenerationSpanning Enhanced Visible Infrared Imager) thermal data which, assuming the best temporal resolution available from space today (i.e., up to $5 \mathrm{~min}$ of refreshing time), might be tested as a space-based "early warning" system to promptly identify anomalous events at COVA and activate intensive monitoring surveys and campaigns.
Acknowledgements. This work has been carried out in the framework of the scientific agreement among Basilicata region, the National Research Council - Institute of Methodologies for Environmental Analysis and the Osservatorio Ambientale Val d'Agri.

The authors would like to thank Vincenzo Lisandrelli, from the ENI S. p. A Divisione E\&P Distretto di Produzione Val d'Agri for providing data about the Val d'Agri Oil Center production.

Edited by: V. Lapenna

Reviewed by: three anonymous referees

\section{References}

Baldassarre, G., Benigno, G., Corrado, R., Coviello, I., Filizzola, C., Lacava, T., Marchese, F., Mazzeo, G., Paciello, R., Pergola, N., Sannazzaro, F., Serio, S., and Tramutoli, V.: Assessment of the Robust Satellite Technique (RST) in real time detection of summer fires, Fifth International Workshop on the Analysis of Multitemporal Remote Sensing Images (MultiTemp), 216-223, 8-30 July 2009, Groton, Connecticut, USA, 2009.

Casadio, S., Arino, O., and Serpe, D.: Gas flaring monitoring from space using the ATSR instrument series, Remote Sens. Environ., 116, 239-249, 2012a.

Casadio, S., Arino, O., and Minchella, A.: Use of ATSR and SAR measurements for the monitoring and characterisation of nighttime gas flaring from off-shore platforms: The North Sea test case, Remote Sens. Environ., 123, 175-186, 2012 b.

Cholakov, G. St.: Control of Pollution in the Petroleum Industry, Pollution Control Technologies, Vol. III, 86-107, available at: http://www.eolss.net/sample-chapters/c09/e4-14-04-03.pdf (last access: December 2013), 2009.

Croft, T. A.: Night-time images of the earth from space, Sci. Am., 239, 68-79, 1978.

Cuomo, V., Filizzola, C., Pergola, N., Pietrapertosa, C., and Tramutoli, V.: A self-sufficient approach for GERB cloudy radiance detection, Atmos. Res., 72, 39-56, 2004.

Dehn, J., Dean, K. G., and Engle, K.: Thermal monitoring of North Pacific volcanoes from space, Geology, 28, 755-758, 2000.

Elvidge, C. D., Baugh, K. E., Kihn, E. A., Kroehl, H. W., and Davis, E. R.: Mapping city lights with nighttime data from the DMSP Operational Linescan System, Photogramm. Eng. Remote Sensing, 63, 727-734, 1997.

Elvidge, C. D., Imhoff, M. L., Baugh, K. E., Hobson, V. R., Nelson, I., Safran, J., Dietz, J. B., and Tuttle, B. T.: Night-time lights of the world: 1994-1995, ISPRS J. Photogramm., 56, 81-99, 2001.

Elvidge, C. D., Baugh, K. E., Tuttle, B. T., Howard, A. T., Pack, D. W., Milesi, C., and Erwin, E. H.: A twelve year record of national and global gas flaring volumes estimated using satellite data. Final report to the World Bank, available at: http://siteresources.worldbank.org/INTGGFR/Resources/ DMSP_flares_20070530_b-sm.pdf (last access: December 2013), 2007.

Elvidge, C. D., Ziskin, D., Baugh, K. E., Tuttle, B. T., Ghosh, T., Pack, D. W., Erwin, E. H., and Zhizhin, M.: A fifteen year record of global natural gas flaring derived from satellite data, Energies, 2, 595-622, 2009.

Elvidge, C. D., Baugh, K. E., Anderson, S., Ghosh, T., and Ziskin, D.: Estimation of gas flaring volumes using NASA MODIS fire 
detection products, NOAA National Geophysical Data Center (NGDC), annual report, 8 February 2011.

Elvidge, C. D., Baugh, K. E., Hsu, F. C, Zhizhin, M., and Ghosh, T.: Improving Global Observations of Gas Flares With Data From the Suomi NPP Visible Infrared Imaging Radiometer Suite (VIIRS), GGFR GLOBAL FORUM London, 24-25 October, 2012.

Elvidge, C. D., Zhizhin, M., Hsu, F. C., and Baugh K. E.: VIIRS Nightfire: Satellite Pyrometry at Night, Remote Sens., 5, 44234449, doi:10.3390/rs5094423, 2013.

EPA: Environmental Protection Agency (EPA), available at: http:// www.epa.gov/airquality/oilandgas/basic.html, last updated on 10 October 2012 (last access: December 2013), 2012.

Filizzola, C., Baldassarre, G., Benigno, G., Corrado, R., Coviello, I., Lacava, T., Marchese, F., Mazzeo, G., Paciello, R., Pergola, N., Sannazzaro, F., Serio, S., and Tramutoli, V.: Automatic RSTbased system for a rapid detection of fires, Proceedings of the VI International Conference on Forest Fire Research (ICFFR), edited by: Viegas, D. X., 43 pp. (proceeding of 15 pages), 2010.

Flasse, S. P. and Ceccato, P.: A contextual algorithm for AVHRR fire detection, Int. J. Remote Sens., 17, 419-424, doi:10.1080/01431169608949018, 1996.

Giglio, L., Descloitres, J., Justice, C. O., and Kaufman, Y.: An enhanced contextual fire detection algorithm for MODIS, Remote Sens. Environ., 87, 273-282, 2003.

Ismail, O. S. and Umukoro, G. E.: Global Impact of Gas Flaring, Energy and Power Engineering, 4, 290-302, doi:10.4236/epe.2012.44039, 2012.

Kaufman, Y. J., Justice, C. O., Flynn, L. P., Kendall, J. D., Prins, E. M., Giglio, L., Ward, D. E., Menzel, W. P., and Setzer, A. W.: Potential global fire monitoring from EOS-MODIS, J. Geophys. Res., 103, 32215-32238, 1998.

Kervyn, M., Harris, A., Mbede, E., Belton, F., Jacobs, P., and Ernst, G. G. J.: MODLEN: A semi automated algorithm for monitoring small-scale thermal activity at Oldoinyo Lengai Volcano, Tanzania, Quantitative Geology from Multiple Sources, IAMG Annual Conference, Extended abstract with conference volume, Liège, 3-8 September 2006.

Local Report ENI: Local Report Ente Nazionale Idrocarburi (ENI) in Basilicata, available at: http://www.eni. com/it_IT/attachments/sostenibilita/impegno-sostenibilita/ eni-in-basilicata.pdf (last access: December 2013), 2012 (in Italian).

Marchese, F., Filizzola, C., Genzano, N., Mazzeo, G., Pergola, N., and Tramutoli, V.: Assessment and improvement of a Robust Satellite Technique (RST) for thermal monitoring of volcanoes, Remote Sens. Environ., 115, 1556-1563, 2011.

Marchese, F., Lacava, T., Pergola, N., Hattori, K., Miraglia, E., and Tramutoli, V.: Inferring phases of thermal unrest at Mt. Asama (Japan) from infrared satellite observations, J. Volcanol. Geotherm. Res., 237-238, 10-18, 2012.

Muirhead, K. and Cracknell, A. P.: Identification of gas flares in the North Sea using satellite data, Int. J. Remote Sens., 5, 199-212, doi:10.1080/01431168408948798, 1984.
NOAA-NGDC, VIIRS Nightfire, Nighttime Detection and Characterization of Combustion Sources: available at: http://ngdc.noaa. gov/eog/viirs/download_viirs_fire.html, (last access: December 2013), 2013.

Noguchi, T., Ohno, N., Hattori, K., and Oyama, K: Detection of thermal changes possibly associated with volcanic activity and discrimination of faint changes from MODIS, J. Asian Earth Sci., 41, 467-475, 2011.

Ohio Epa: Ohio Environmental Protection Agency (Ohio Epa): "Exploration, Production and Processing of Oil and Natural Gas from the Marcellus and Utica Shales in Ohio", available at: http: //www.epa.state.oh.us/portals/0/Generalpdfs/gasflaring.pdf (last access: December 2013), May 2012.

Rapporto Istruttorio Regione Basilicata, Dipartimento Ambiente, Territorio, Politiche della Sostenibilità "ALLEGATO 3" - artt. 29 quater e 29 sexies del Decreto Legislativo 3 aprile 2006 no. 152, Aggiornamento dell'A.I.A. relativa all'impianto denominato “Centro Olio Val D’Agri”, 2011 (in Italian).

Steffke, A. M. and Harris, A. J.: A review of algorithms for detecting volcanic hot spots in satellite infrared data, Bull. Volcanol., 73, 1109-1137, 2011.

Tramutoli, V.: Robust AVHRR Techniques (RAT) for Environmental Monitoring: theory and applications. Earth Surface Remote Sensing II, Giovanna Cecchi, Eugenio Zilioli, Editors, Proceedings of SPIE, 3496, 101-113, 1998.

Tramutoli, V.: Robust Satellite Techniques (RST) for natural and environmental hazards monitoring and mitigation: ten years of successful applications, The 9th International Symposium on Physical Measurements and Signatures in Remote Sensing, edited by: Liang, S., Liu ,J., Li, X., Liu, R., Schaepman, M., Beijing, China, ISPRS, Vol. XXXVI (7/W20), 792-795, ISSN 1682-1750, 2005.

Tramutoli, V.: Robust Satellite Techniques (RST) for Natural and Environmental Hazards Monitoring and Mitigation: Theory and Applications, Fourth International Workshop on the Analysis of Multitemporal Remote Sensing Images. 18-20 July, 2007, Louven, Belgium, doi:10.1109/MULTITEMP.2007.4293057, 2007.

Van Manen, S. M. and Dehn, J.: Satellite remote sensing of thermal activity at Bezymianny and Kliuchevskoi from 1993 to 1998, Geology, 37, 983-986, 2009.

Welch, R.: Monitoring urban population and energy utilization patterns from satellite data, Remote Sens. Environ., 9, 1-9, 1980.

Wooster, M. J., Shukiv, B., and Oertel, D.: Fire radiative energy for quantitative study of biomass burning: Derivation from the BIRD experimental satellite and comparison to MODIS fire products, Remote Sens. Environ., 86, 83-107, 2003.

World Bank, Global Gas Flaring Reduction, available at: http://web.worldbank.org/WBSITE/EXTERNAL/TOPICS/ EXTOGMC/EXTGGFR/0,, contentMDK:21023030 menuPK: 2856589 pagePK:64168445 piPK:64168309 theSitePK: 578069,00.html (last access: December 2013), 2012.

Wright, R., Flynn, L., Garbeil, H., Harris, A., and Pilger, E.: Automated volcanic eruption detection using MODIS, Remote Sens. Environ. 82, 135-155, 2002. 